\title{
Nonlinear Vibroimpact Characteristics of a Planetary Gear Transmission System
}

\author{
Jianxing Zhou, ${ }^{1,2}$ Wenlei Sun, ${ }^{1}$ and Liang Yuan ${ }^{1}$ \\ ${ }^{1}$ School of Mechanical Engineering, Xinjiang University, Urumqi 830047, China \\ ${ }^{2}$ Center for Post-Doctoral Studies of Mechanical Engineering, Urumqi 830047, China \\ Correspondence should be addressed to Jianxing Zhou; jianzhou82923@163.com
}

Received 31 July 2015; Revised 8 November 2015; Accepted 23 November 2015

Academic Editor: Juan P. Amezquita-Sanchez

Copyright (c) 2016 Jianxing Zhou et al. This is an open access article distributed under the Creative Commons Attribution License, which permits unrestricted use, distribution, and reproduction in any medium, provided the original work is properly cited.

\begin{abstract}
In order to research the vibroimpact characteristics of a planetary gear transmission system under high speed and lightly loaded conditions, a new modeling method is proposed. In the modeling process, linear spring was used to simulate gear mesh elasticity under heavy load cases, and Hertz contact theory was used to calculate the contact force of gear pair under light load cases. Then, effects of the working conditions on the system vibroimpact characteristics are analyzed. The results show that, with input speed growing, the mesh force produced obvious fluctuations on the resonance frequencies of the sun gear and carrier torsion vibration, ring gear's transverse vibration under the heavy load. Under light load condition, the collision vibration occurs in the gear pair; the changing trend of the contact force shows strongly nonlinear characteristics. The time of mesh-apart in gears pair decreases gradually as the load is increased; until it reaches collision vibration threshold value, the gear pair is no longer mesh-apart. With increasing of the input speed, the time of mesh-apart is decreased gradually; the fluctuation amplitude of contact force shows a linearly increasing trend. The study provides useful theoretical guideline for planetary gear transmission low-noise design.
\end{abstract}

\section{Introduction}

Planetary gear transmission is characterized by large gear ratio, compact structure, and light weight and has been widely applied to various industries. Planetary gear transmission has become an indispensable key device in main power system in high speed and heavy load transmission device such as helicopter transmission and marine transmission; however, the wear in tooth profile and error in machining are likely to result in gear backlash in gear pair, which will bring repetitive collision phenomenon of contact [1], contact loss, and recontact between gears. At high speed, the gear transmission shows more obvious impact effect and leads to strong vibration, exerting an adverse influence on working performance and service life of equipment.

Impact process is a complex process associated with relative speed of objects in contact, geometrical shape of contact surface, duration of contact, and local plastic deformation [2]. High speed impact between gears in gear dynamics means gear's rapid rebound from the moment being mesh-apart in contact each other, which is equivalent to low speed impact in structural dynamics, so the impact between gear teeth can be described by classical impact dynamics theory [3].

Typical analyses model of planetary gear transmission can be divided into two main groups: finite element model and lumped parameter model. The lumped parameter model is the most common model used to study dynamic behaviors of the planetary gear system. With the development of research, this kind of analytical model has developed from initial purely torsional model to torsion-transverse vibration coupling and torsion-transverse-axial coupling model [4]. Meanwhile, in order to make the analytical model closer to the physical prototype, a growing number of factors and application conditions are involved consecutively, such as external excitation [5], effect of oil film rigidity asymmetry of sliding bearing [6], and clearance of the bearing [7].

Same scholars use a clearance-type nonlinear restoring function in the model to describe the gear mesh and backlash. Walha et al. found that gear contact is characterized by a periodically changing stiffness and a backlash can lead to 


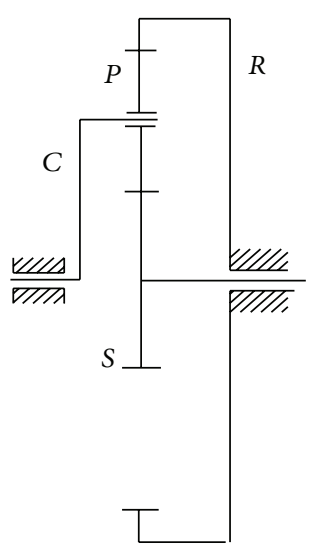

(a) Planetary gear transmission system sketch

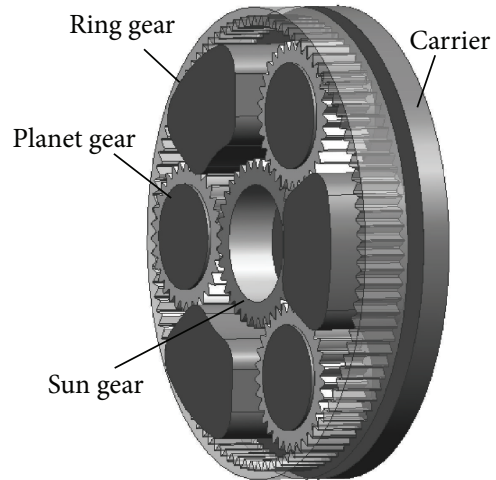

(b) Assembly model for planetary gear transmission system

FIGURE 1: The planetary gear transmission system sketch and three-dimensional model.

loss of the contact [8]. Kahraman et al. analyzed steady state response period solution of time varying system with backlash [9]. Sun et al. made a study of influence of time varying mesh stiffness, error, and backlash on nonlinear dynamic behavior of system [10]. Eritenel and Parker examined nonlinearity due to partial contact loss, where segments of contact are lost between meshing teeth, using a rigid body dynamic model [11].

Through using this kind of model, the gear tooth flank backlash is considered, and the contact loss phenomenon and nonlinear dynamic characteristics are simulated. However, when the gear tooth recontact, the gear pairs impact will happened. The impact force and its influence on the system dynamics cannot be solved by this kind model. Barthod et al. indicate that the rattling noise is produced by gear system vibroimpact, and the rattling noise shall be enhanced evidently with the increase of excitation in frequency and amplitude [12]. Dogan et al. found that the influencing factors of rattling noise in reducer are divided into geometric parameter of gear (such as module, number of teeth, helix angle, and backlash) and parameter of operating condition (such as angular acceleration and excitation frequency) [13]. Kadmiri et al. consider that the impact load due to gear rattling is also associated with coefficient of impact recovery (such as structure material and contact shape and lubrication) [14]. Presently, there is almost no document about research on impact and vibration of planetary gear transmission system.

Finite element model has more geometry information of the tooth, so its result is more precise and intuitive. Generally, finite element model is used to analyze the gear loaded tooth contact analysis (LTCA) $[15,16]$, load sharing between the gears [17], and time varying meshing stiffness calculation [18]. The finite element models for dynamic response are rare because they require significant computational effort [19].

The paper presents vibroimpact analytical model building method of planetary gear transmission system using the lumped parameter method, in which the Hertz contact theory is induced to describe impact of the gear pairs, the influence of operating condition of system on dynamic engaging force
TABLE 1: The planetary gear transmission system parameters.

\begin{tabular}{lccc}
\hline Parameter & Sun gear & Planet wheel & Ring gear \\
\hline Number of teeth & 34 & 31 & 96 \\
Face width $(\mathrm{mm})$ & 42 & 42 & 42 \\
Module $(\mathrm{mm})$ & 3 & 3 & 3 \\
Pressure angle $\left(^{\circ}\right)$ & 28 & 28 & 28 \\
Modification coefficient & -0.02 & 0.02 & 0.02 \\
Mass & 2.7 & 2.5 & 5.3 \\
Moment of inertia & 0.008 & 0.007 & 0.178 \\
\hline
\end{tabular}

is calculated, and the system vibroimpact characteristics are analyzed under the conditions of heavy load and light load.

\section{Analytical Model}

2.1. Analytical Model for Planetary Gear Transmission. The planetary gear transmission system given in the paper is as shown in Figure 1(a), the symbol $R$ is ring gear, $S$ is sun gear, $P$ is planet wheel, and $C$ is planet carrier. The system is composed of a sun gear, 3 planet wheels, a planet carrier, and a ring gear. Sun gear is input part, adopting slender elastic axis for connection to function as elastic floating action. Ring gear is fixed; planet carrier is output end.

The basic parameters for experimental prototype are as shown in Table 1; its moment of inertia and mass are obtained by UG NX through 3-dimension solid modeling. The 3dimension assembly model for transmission system is as shown in Figure 1(b).

\subsection{Planetary Gear Transmission System Dynamic Model.} $2 \mathrm{~K}-\mathrm{H}$ planetary gear transmission system dynamic model is shown in Figure 2, the support stiffness, torsional stiffness, and gear mesh stiffness are replaced by spring, planet carrier taken as origin of coordinates, horizontal direction taken as $X$-direction, and vertical direction taken as $Y$-direction, and $\theta$ is direction of torsional angle. The symbol $K$ is stiffness in 


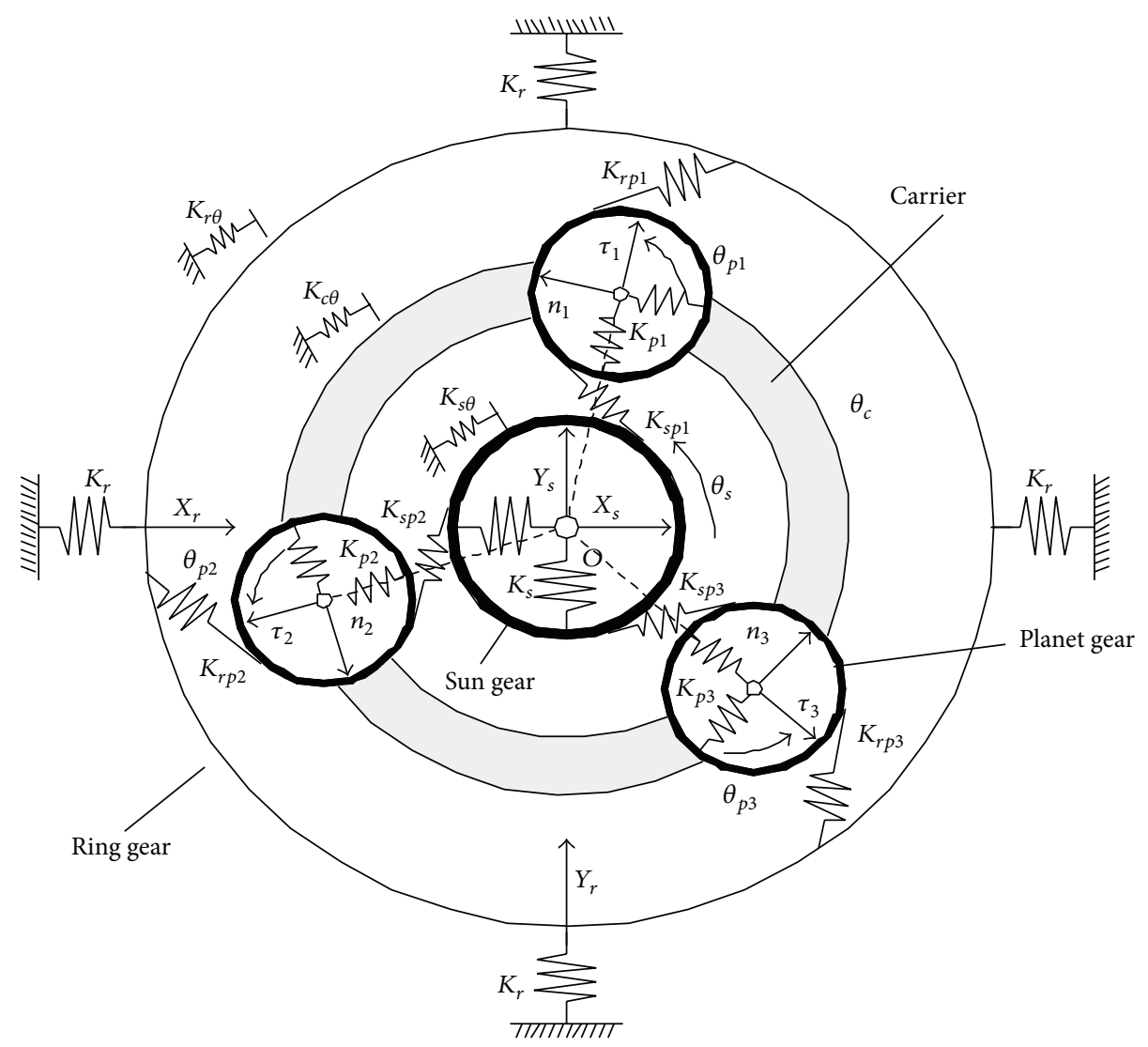

FIGURE 2: The planetary gear transmission system dynamic model.

the figure. $K_{s}$ is support stiffness of sun gear, $K_{s \theta}$ is torsional stiffness of sun gear in model; planet gear adopts bearing for support; $k_{p i}$ is support stiffness of number $i(i=1,2,3)$ planet wheel; $K_{r}$ is support stiffness of ring gear, adopting four symmetric positions (on top, bottom, left, and right, resp.) to constrain annular gear structure. $k_{s p i}$ and $k_{r p i}$ in model are gear mesh stiffness for sun gear and planet gear as well as planet gear and ring gear, respectively.

A number of simplifying assumptions were employed in establishing the gear transmission subsystem dynamic model through lumped parameter method:

(1) The gear body and planet carrier are assumed to be rigid. The flexibilities of the gear teeth at each gear mesh interface are modeled by a spring having periodically time varying stiffness.

(2) The engaging force between gears always exists along the gear line of action. Each support part's flexibility is included in the form of a linear spring, and the support stiffness is constant.

(3) Planet gears are surrounding the central gear (including sun gear and planet carrier). Every planet gear has the same mass, moment of inertia, and support stiffness. Friction during gear engagement is neglected.

(4) Each planet gear has the same meshing stiffness with the sun gear except for different phase positions. The support stiffness of sun gear, ring gear, and planet carrier in all directions is the same.

(5) The gear-shaft connections were assumed to be rigid, ignoring the stiffness of the connections and any consequent relative torsional motion between the shaft and gear hub.

Then in the system $X$ and $Y$ are transverse microdisplacement; $\theta$ is torsional microdisplacement. Supposing that all gears have degree of freedom along transverse and torsional directions, the generalized displacement vector of the system is as follows:

$$
\{X\}=\left\{x_{s} y_{s} \theta_{s}, x_{p 1} y_{p 1} \theta_{p 1}, \ldots, x_{r} y_{r}\right\}^{T}
$$

2.3. Engaging Force and Impact Force between Gear Pair. When load is large enough, the gear pair are always engaged and no contact loss happened, so engaging force generated on two tooth flanks and elastic deformation are in linear proportion. At this time, the gear pair stiffness is replaced by linear spring; the dynamic model for sun gear and planet gear is as shown in Figure 3. Both the torsion and transverse displacement of the gears have an effect on their engaging process, so all microdisplacements are translated to action 


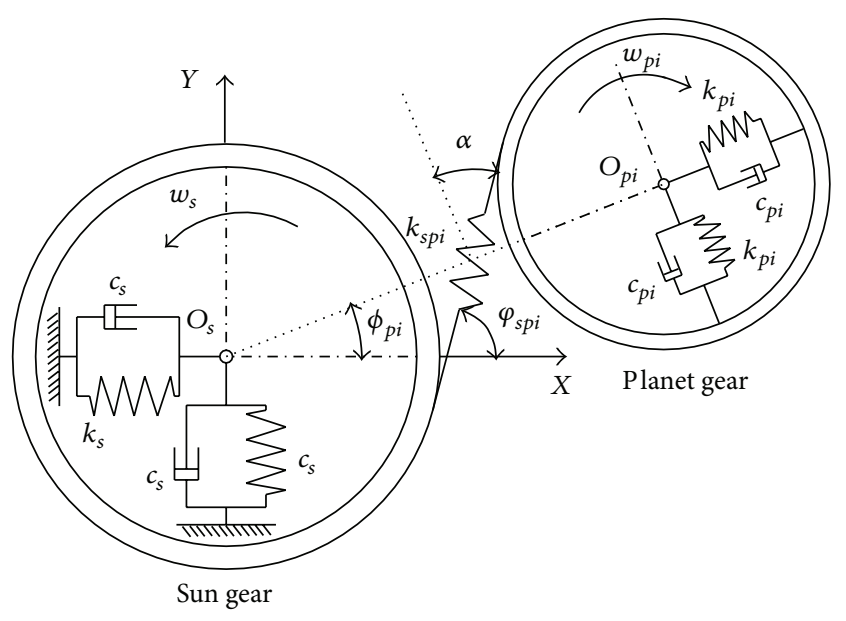

Figure 3: The dynamic model of sun gear and planet gear.

line of contact. When engaging spring compression is defined to be positive and its tension is defined to be negative, then

$$
\begin{aligned}
\delta_{s p i}= & x_{s} \cos \varphi_{s p i}+y_{s} \sin \varphi_{s p i}+u_{s}-x_{p i} \sin \alpha \\
& -y_{p i} \cos \alpha-u_{p i}-e_{s p i}(t),
\end{aligned}
$$

where

$$
\begin{aligned}
\varphi_{s p i} & =\phi_{c}-\alpha+\phi_{p i}+\frac{\pi}{2}, \\
u_{s} & =\theta_{s} r_{s} \\
u_{p i} & =\theta_{p i} r_{p i} \\
\phi_{c} & =w_{c} t
\end{aligned}
$$

in which $\alpha$ is working pressure angle and $\phi_{p i}$ is phase angle $\left(\phi_{i}=2 \pi(i-1) / 3\right) . r_{s}, r_{p i}$ are base circle radius of sun gear and planet gear; $e_{s p i}(t)$ is engaging error.

Here, the engaging force is

$$
F_{s p i}=k_{s p i} \delta_{s p i}+c_{s p i} \dot{\delta}_{s p i} .
$$

When transmission system load is light, the load is unable to make two tooth flanks maintain constant engaging, so the gear pair comes into instantaneous impact on two tooth flanks. Therefore, driven gear shall speed up in a second to separate from driving gear to reciprocate in such a way that the gear pair contact loss phenomenon appeared. In this process, the impact force is produced between the contacted gears. The paper describes elastic effect between gear teeth by Hertz contact mechanics. Under this condition, the dynamic model for sun gear and planet gear is as shown in Figure 4, in which the tooth flanks in contact between sun gear and planet gear are connected by contact spring and $k_{c s p i}$ is tooth flank contact stiffness.

In the gear engagement process, with the influence of errors and structure deformations, the direction of gear engaging force is not strictly along the theoretical action line. Since such errors and deformations are small enough,

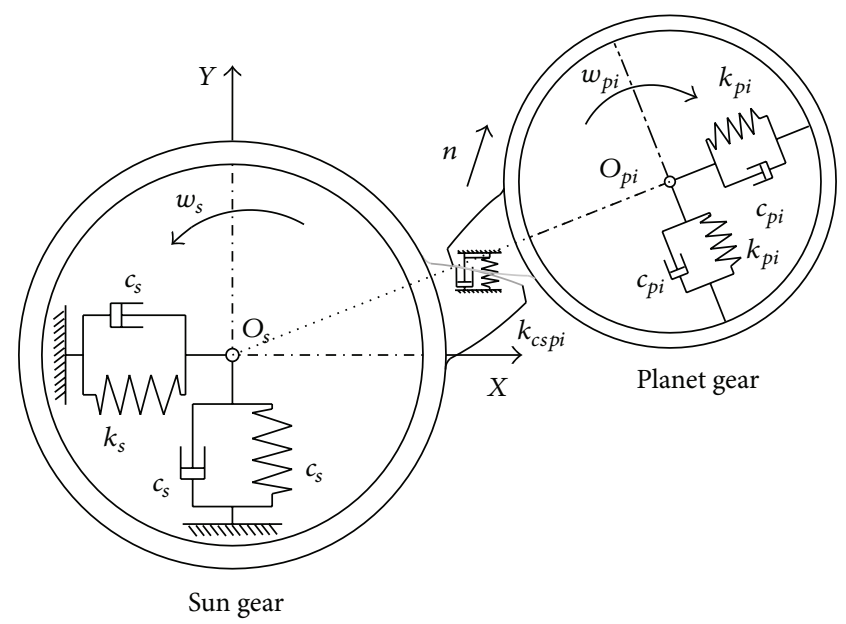

FIGURE 4: The vibroimpact model of sun gear and planet gear.

here we suppose that the gear engaging force is still along theoretical action line, and the two gear teeth in contact shall be taken as two bodies in impact. Taking material damping into consideration, the generalized Hertz formula of the sun gear and planet gear is shown as the following forms:

$$
F_{s p i}=k_{c s p i} \delta_{s p i}^{n}+D_{c s p i}(x) \dot{\delta}_{s p i} \quad n=1.5,
$$

where $\delta$ is relative deformation of two bodies in contact and $\dot{\delta}$ is relative contact speed. Damping coefficient is $D(x)=$ $\lambda x^{n}$, in which $\lambda$ is hysteresis damping coefficient. $k_{c s p i}$ is Hertz stiffness in elasticity theory; it is dependent on material characteristic and radius of curvature, as shown in the following:

$$
\begin{aligned}
& k_{c s p i}=\frac{4}{3 \pi\left(h_{1}+h_{2}\right)}\left[\frac{r_{1} r_{2}}{r_{1}+r_{2}}\right]^{1 / 2} \\
& h_{i}=\frac{1-v_{i}^{2}}{\pi E_{i}}, i=1,2,
\end{aligned}
$$

where $r_{1}$ and $r_{2}$ are sun gear and planet gear tooth profile radius of curvature, respectively, and $E_{i}$ and $v_{i}$ are modulus of elasticity and Poisson's ratio.

The speed relation of hysteresis damping coefficient $\lambda$ before and after impact according to energy relation and kinetic energy loss during impact is calculated based on Newton's coefficient of recovery $e$,

$$
\Delta T=\frac{1}{2} \bar{m}\left(v_{10}-v_{20}\right)^{2}\left(1-e^{2}\right),
$$

where $\bar{m}=m_{1} m_{2} /\left(m_{1}+m_{2}\right)$.

In addition, impact is energy loss and indicated by

$$
\Delta T=\oint D \dot{\delta} d \delta \approx 2 \int_{0}^{\delta_{m}} \lambda \delta^{n} \dot{\delta} d \delta=\frac{2}{3} \frac{\lambda}{k} \bar{m}\left(v_{10}-v_{20}\right)^{3} .
$$

Coefficient of recovery and hysteresis damping coefficient satisfy

$$
\lambda=\frac{3}{4} \frac{k\left(1-e^{2}\right)}{v_{10}-v_{20}} .
$$




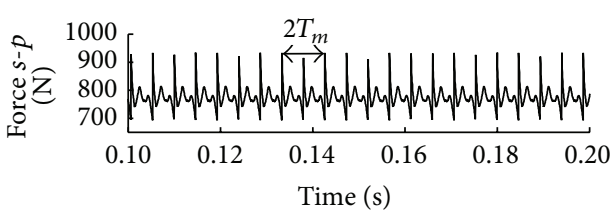

(a) Time history of sun gear and planet gear meshing force

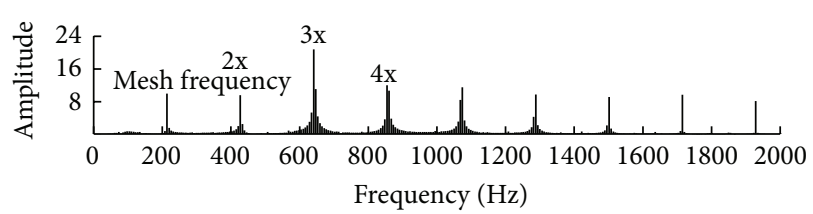

(b) Sun gear and planet gear meshing force spectra

FIGURE 5: The dynamic force of sun gear and planet gear.

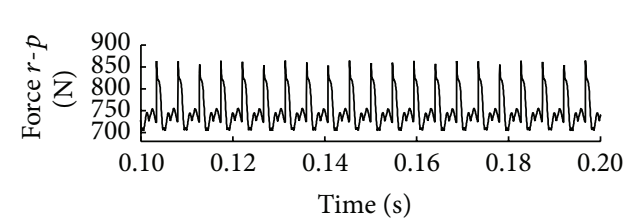

(a) Time history of sun gear and planet gear meshing force

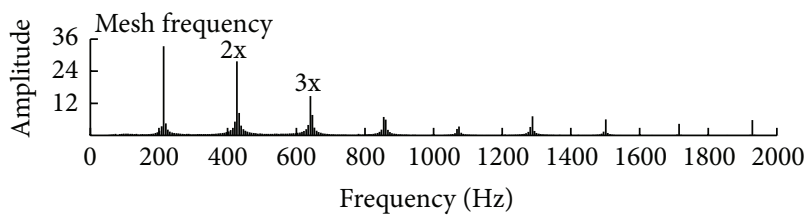

(b) Sun gear and planet gear meshing force spectra

FIGURE 6: The dynamic force of ring gear and planet gear.

Contact force is equivalent to

$$
f=k \delta^{n}\left(1+\frac{3}{4} \frac{1-e^{2}}{v_{10}-v_{20}} \dot{\delta}\right) .
$$

The above-mentioned formula reveals the relation between contact force and coefficient of recovery and speed before and after impact.

2.4. Impact and Vibration Model for Planetary Gear Transmission System. Differential equation for system vibration is built based on stress condition of all parts

$$
\begin{aligned}
& m_{s} \ddot{x}_{s}+c_{s} \dot{x}_{s}-\sum_{i=1}^{3} F_{s p i} \cos \varphi_{s p i}+k_{s} x_{s}=0, \\
& m_{s} \ddot{y}_{s}+c_{s} \dot{y}_{s}+\sum_{i=1}^{3} F_{s p i} \sin \varphi_{s p i}+k_{s} y_{s}=0, \\
& m_{s p i} \ddot{u}_{s}+c_{\theta} \dot{u}_{s}+\sum_{i=1}^{3} F_{s p i}+k_{\theta} u_{s}=\frac{T_{\text {in }}}{r_{s}}, \\
& m_{p i} \ddot{x}_{i}-k_{p i} \delta_{p i x}-F_{s p i} \sin \alpha+F_{r p i} \sin \alpha=0, \\
& m_{p i} \ddot{y}_{i}-k_{p i} \delta_{p i y}-F_{s p i} \cos \alpha-F_{r p i} \cos \alpha=0, \\
& m_{e q, p i} \ddot{u}_{i}-F_{r p i}+F_{s p i}=0, \\
& m_{e q c} \ddot{u}_{c}+\sum_{i=1}^{N} c_{p i} \dot{\delta}_{c p i y}+c_{c u} \dot{u}_{c}+\sum_{i=1}^{N} k_{p i} \delta_{c p i y}+k_{c u} u_{c} \\
& =\frac{T_{\mathrm{out}}}{r_{c}},
\end{aligned}
$$

$$
\begin{aligned}
& m_{r} \ddot{x}_{r}+c_{r} \dot{x}_{r}-\sum_{i=1}^{3} F_{r p i} \cos \varphi_{r p i}+k_{r} x_{r}=0, \\
& m_{r} \ddot{y}_{r}+c_{r} \dot{y}_{r}+\sum_{i=1}^{3} F_{r p i} \sin \varphi_{r p i}+k_{r} y_{r}=0, \\
& m_{r p i} \ddot{u}_{r}+c_{r \theta} \dot{u}_{r}+\sum_{i=1}^{3} F_{r p i}+k_{r \theta} u_{r}=0,
\end{aligned}
$$

where $m_{s p i}$ is equivalent mass of sun gear and number $i$ planet gear, $m_{s p i}=\bar{m}_{s} \bar{m}_{p i} /\left(\bar{m}_{s}+\bar{m}_{p i}\right), \bar{m}_{s}=I_{s} / R_{s}^{2}, \bar{m}_{g}=I_{p i} / R_{p i}^{2}$, $m_{p i}$ is mass of planet gear, $m_{s}$ is mass of sun gear, and $m_{r}$ is mass of ring gear.

\section{Dynamic Characteristic of System under the Action of Large Load}

3.1. Engaging Force of System. When the load act on the gear train is heavy, the tooth flanks of gear pair stay in contact all the time; the dynamic load of system is calculated at the speed of $500 \mathrm{r} / \mathrm{min}$ and under the load of $500 \mathrm{~N} \cdot \mathrm{m}$.

The dynamic force of sun gear and planet gear is as shown in Figure 5(a), it is observed that dynamic load shows cyclical variation, its cycle is $T_{m}$ (time of the mesh cycle), the average value of dynamic load is $774 \mathrm{~N}$, and the amplitude in fluctuation is $168 \mathrm{~N}$. As shown in Figure 5(b), the main frequency component in dynamic load of sun gear and planet gear is engaging frequency $(212 \mathrm{~Hz}), 2$-multiple-frequency, 3multiple-frequency, and 4-multiple-frequency components, in which 3-multiple frequency component is the highest in energy.

The dynamic force of planet gear and ring gear is as shown in Figure 6(a); we can observe that the average value of dynamic load is $750 \mathrm{~N}$; the amplitude in fluctuation is $118 \mathrm{~N}$. As shown in Figure 6(b), the main frequency component in 


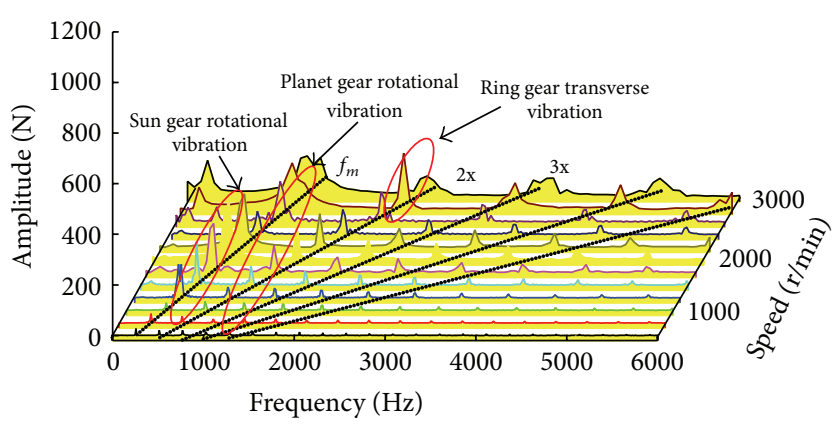

(a) The dynamic force waterfall curve of the sun gear and planet gear

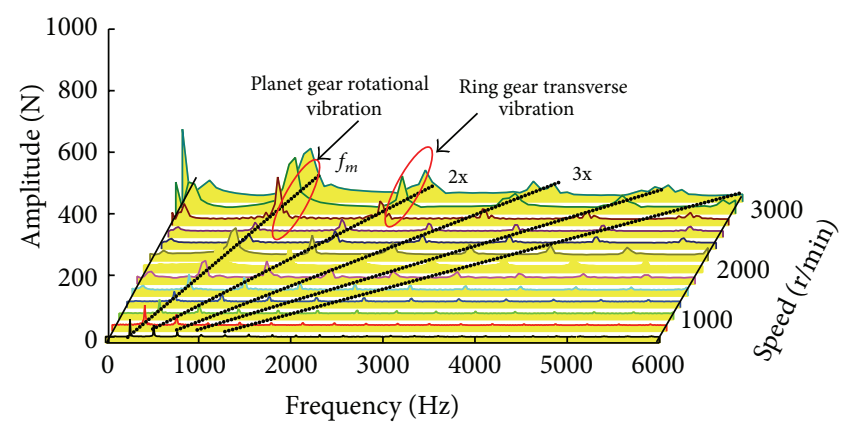

(b) The dynamic force waterfall curve of the planet gear and ring gear

FIGURE 7: The dynamic force waterfall curve of the sun gear and planet gear.

dynamic load is engaging frequency, 2-multiple frequency, and 3-multiple frequency component, in which engaging frequency is the highest in energy.

\subsection{Load Spectrum of System under Continuous Operating} Condition. The vibration and excitation of planetary gear transmission system are composed of engaging frequency and multiple frequency; in addition, the relation between excitation component and natural frequency of transmission system also has direct effect on vibration amplitude. The dynamic response of gear box is as shown in Figure 7 , in which $f_{m}$ is engaging frequency. Since engaging frequency and multiple frequency components are linear proportion with the rotating speed, therefore, all harmonic components in excitation of gear are in radial distribution. The engaging frequency of dynamic load of sun gear and planet gear appears as obvious peak value around natural frequency $(412 \mathrm{~Hz}$, there are two orders of repetition frequency; the corresponding speed is $706 \mathrm{r} / \mathrm{min}$ ) of sun gear rotational vibration. Given engaging frequency component from $2500 \mathrm{r} / \mathrm{min}$ to $3000 \mathrm{r} / \mathrm{min}$ and second harmonic component of $1500 \mathrm{r} / \mathrm{min}$, under the action of third harmonic at $1000 \mathrm{r} / \mathrm{min}$, there are the highest peak appearing around natural frequency of planet gear rotational vibration $(889 \mathrm{~Hz}$, there are three repetition frequencies, $919 \mathrm{~Hz}$ ) and rotation vibration $(1046 \mathrm{~Hz})$ of planet carrier, in which $3000 \mathrm{r} / \mathrm{min}$ engaging frequency component is the highest in peak value. There is also peak value around natural frequency of ring gear transverse vibration $(1791 \mathrm{~Hz})$ under the action of $2800 \mathrm{r} / \mathrm{min}$ of second harmonic component.

Although vibration of parametric excitation of the gear system is linear matter, the dynamic load frequency components are complex due to coupled effect of the time varying mesh stiffness and the contact force of tooth profile. Meanwhile, different speed shall have a direct effect on excitation frequency component. In order to reveal the influence of rotating speed on fluctuation in dynamic load of bearing, the 1st harmonics variations of $F_{s p i}$ and $F_{r p i}$ have been calculated within the range of the main operating speed $(500 \mathrm{r} / \mathrm{min} \sim$ $3000 \mathrm{r} / \mathrm{min}$ ) as shown in Figure 8.

The first-order harmonic component variation of engaging force is divided into three sections, namely $a, b$, and $c$. The first section is from $500 \mathrm{r} / \mathrm{min}$ to $1050 \mathrm{r} / \mathrm{min}, F_{s p}$ and

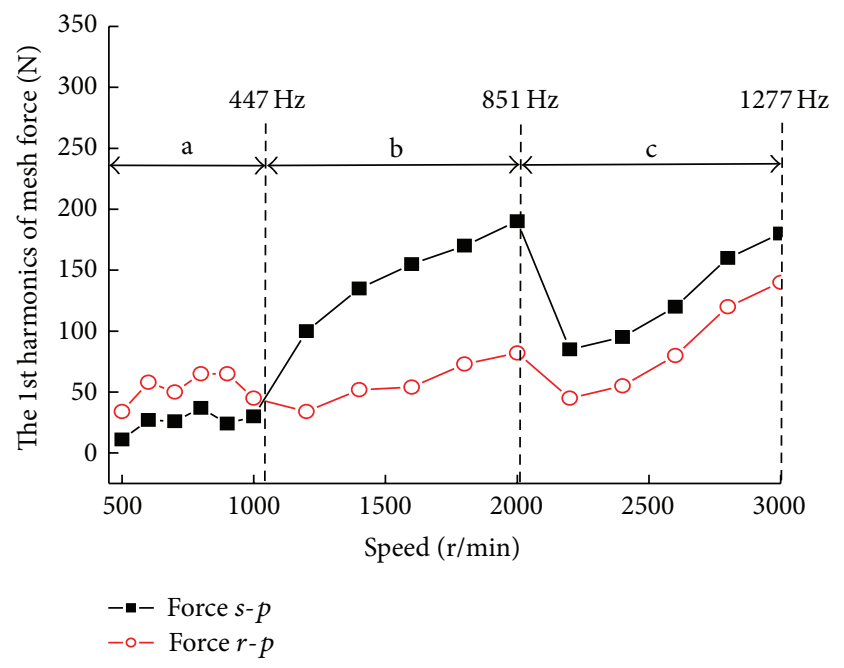

FIgURE 8: The dynamic force first-order harmonic component of ring gear and planet gear under different speed.

$F_{r p}$ increased by degrees with the increase of speed, and this section only contains the first-order nature frequency of sun gear torsional vibration. However, accompanied by trend of fluctuation, $F_{s p}$ is much higher than $F_{r p}$ in speeding up in the section, since the torsional vibration of sun gear has a direct effect on engagement between sun gear and planet gear, and then the component of the dynamic load $F_{s p}$ to approach $F_{r p}$, till they are identical at $1050 \mathrm{r} / \mathrm{min}$; the second section is from $1050 \mathrm{r} / \mathrm{min}$ to $2000 \mathrm{r} / \mathrm{min}$, in which the numbers of system natural frequency are added; there are planet gear transverse vibration $(889 \mathrm{~Hz}, 919 \mathrm{~Hz})$, planet carrier torsional vibration $(1046 \mathrm{~Hz})$. All the vibration modes have a direct effect on engagement of sun gear and planet gear, accordingly, so $F_{s p}$ is increased to a great extent in the section. Since sun gear torsional vibration does not have a direct effect on engagement of ring gear and planet gear, $F_{r p}$ experienced a process of gradual decrease at the beginning of the third section. Then insignificant increase happened to $F_{r p}$ due to the number of system vibration modes being decreased, but only ring gear transverse vibration $(1791 \mathrm{~Hz})$. 


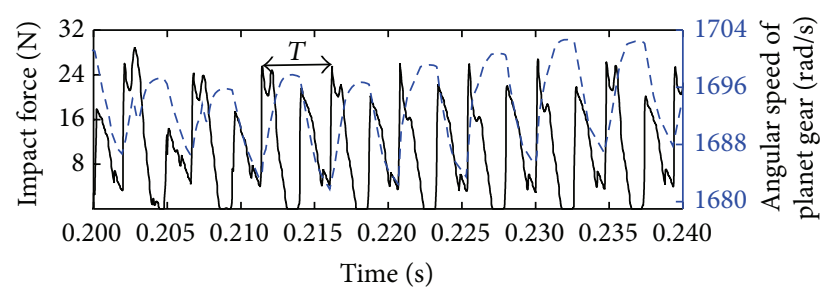

$-\mathrm{A}$

(a) Gear impact force and planet gear angular speed without load

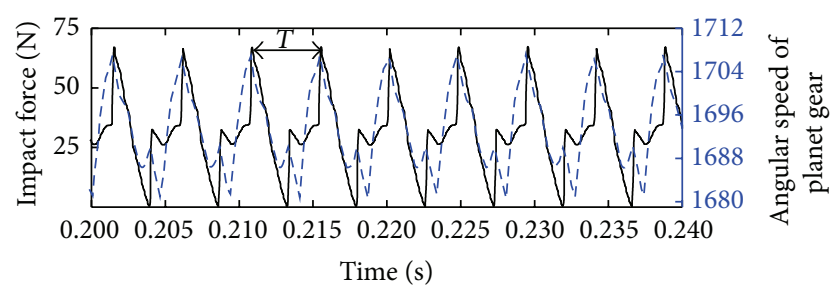

- A

(b) Gear impact force and planet gear angular speed under $M=21 \mathrm{~N} \cdot \mathrm{m}$

FIgURE 9: The dynamic impact force under different load.

\section{Impact and Vibration Characteristic of System under Light Load}

4.1. Influence of Load on Impact Force of Gears. The research of gear system vibroimpact does not take account of structural permanent deformation, but the process for gear from separated to contact is considered. With effect of relative velocity, the gear system is inevitably to bring impact between gear teeth of the driving and driven gear; then large impulsive load must be generated.

At the condition of the speed being $500 \mathrm{r} / \mathrm{min}$ and the load being light and gear contact force being as shown in Figure 9, in which curve A is time domain history of impact force and B is time domain history of angular speed of planet gear, it is observed that the impact force between planet gear and ring gear under the condition of load being 0 is still showing cyclical fluctuation. There is disengagement (the gears are in separate state) appearing in every cycle, when the gear recontact; the impact force is increased rapidly. During the time of gears disengagement, the impact force is 0 as a result of absence of external force, so the planet gear angular speed remains constant in a second.

In addition, we can see that there are two obvious peak values in every cycle, so the second harmonic component is main frequency component of impact force. With the increase of load, the time for disengagement shall gradually shorten. When load is $21 \mathrm{~N} \cdot \mathrm{m}$, the gear pair is in critical state between normal engagement and disengagement, as shown in Figure 9(b). It is observed that the impact force and angular speed of planet gear also show cyclic variation, and only one point on impact forces is intersected with $x$-axis in every cycle (namely, it is equal to 0 ), and the angular speed of planet gear only shows inflection point in the position. It is also found that there is only one larger peak value in one cycle, so engaging frequency component is changed to be the main frequency component of contact force. The variation of impact force shows strong nonlinear feature; the load is not only to affect the average value of the force and amplitude in fluctuation, but also to have a direct effect on frequency components.

The influence of load on vibroimpact of planetary gear transmission system is shown in Figure 10. The gear engagement can be divided into two stages with change of the load;

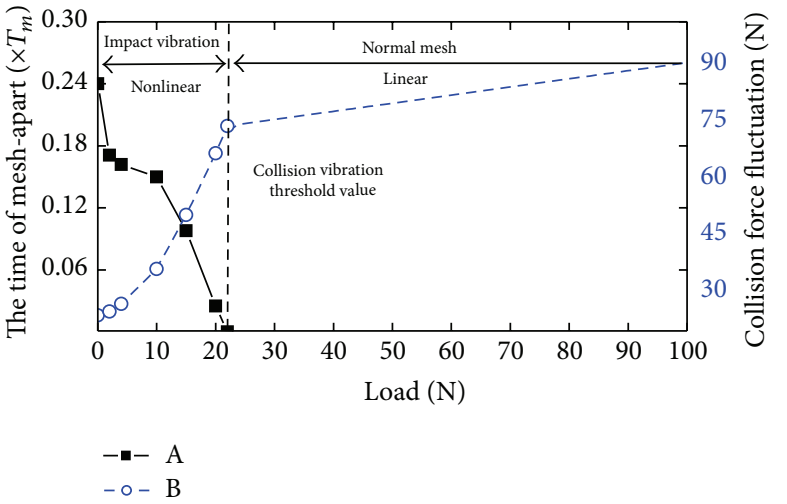

FIgURE 10: The effect of the load on gear vibroimpact characteristics.

the first stage is vibroimpact stage, in which the impact is larger than planet gear moment of retardation:

$$
\left|m_{e q, p i} \ddot{u}_{i}\right| \geq T_{\text {drag }}
$$

where $T_{\text {drag }}$ is moment of retardation dependent on driven gear damping force and load moment.

At this point, gear shall start vibroimpact of engagement, disengagement, and reengagement [20]. In general, time for gear to disengage shall gradually shorten with the increase of load. When load is smaller, since time for disengagement is longer, the time is $0.24 \mathrm{~T}$ under the load which is 0 . Then the load is effectively to reduce the speed of driven gear after impact. With the increase of load, the load shall increase relative impact speed of gear and impact force, so the disengagement time is shortened slowly. When load increases again, time for disengagement shall shorten rapidly again; gear contact force and amplitude in fluctuation show second function quadratic function curve change.

When load is up to threshold value (in the paper it is $21 \mathrm{~N} \cdot \mathrm{m}$ ), gear engagement shall enter into normal engagement, in which gear shall not disengage again. With the increase of load, amplitude in fluctuation of engaging force shall show linear increase, but its increasing speed is reduced compared with that in vibroimpact stage.

4.2. Influence of Rotating Speed on Impact Force of Gear. The influence of rotating speed on engagement of planetary 


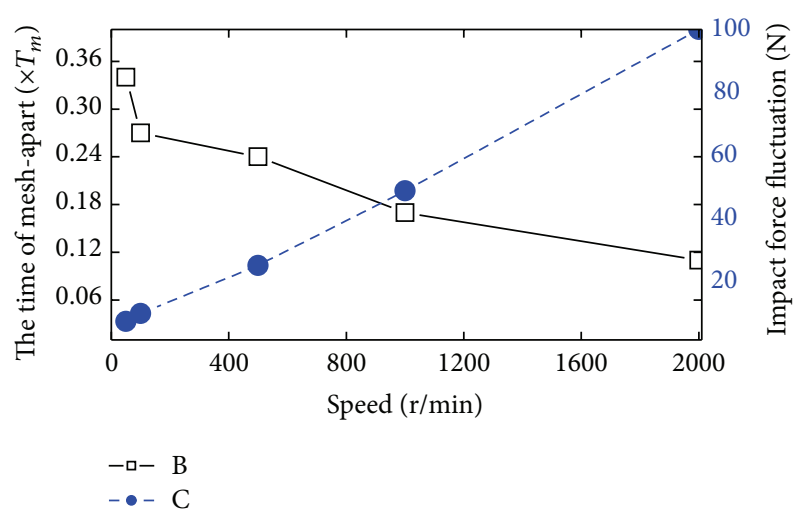

FIGURE 11: The effect of the input speed on gear vibroimpact characteristics.

gear transmission system is shown in Figure 11. When the load is 0 , with the increase of input rotating speed, time for gear to disengage is decreased gradually. At lower rotating speed, the engaging period is longer and the relative rotating speed of gear is lower, so the impact force is smaller and gear shall have longer time to maintain disengagement after impact for one time. When rotating speed is $50 \mathrm{r} / \mathrm{min}$, the time for disengagement is $0.34 \mathrm{~T}$. As the increase of rotating speed, the relative rotating speed of gear is increased, and the impact force and collisional deformation will gradually increase; therefore, the contact time for two tooth flanks is longer, the time for disengagement shall is shorter, when rotating speed is $2000 \mathrm{r} / \mathrm{min}$, and the time for disengagement is reduced to $0.11 T$.

In the process of speed change, since torsional direction of planet gear is unconstrained, with torsional rigidity of sun gear being much smaller than contact rigidity, therefore, the influence of constraint elasticity of two tooth flanks on coefficient of recovery shall be very small; at this time, the impact of gear can be assumed as free body [21], with small influence of external elastic constraint on fluctuation of impact force; therefore, the inherent characteristic of system shall have direct effect on variation in impact force; the amplitude in fluctuation of impact force shall show linear increase with the increase of rotating speed; in addition, it is also observed that threshold value of impact and vibration of gear shall also show linear increase with the increase of speed.

4.3. Influence of Rotating Speed on Floating Trajectory of Center Gear. The floating trajectory of sun gear and ring gear at different input speed under the condition of the load is 0 as shown in Figure 12. We found that the floating range of sun gear increases as the speed increases; it is also subjected to the influence of the system inherent mode of vibration. The floating range at the $1000 \mathrm{r} / \mathrm{min}$ is the largest, because the third harmonic component at $1000 \mathrm{r} / \mathrm{min}$ shall meet the frequency of the planet carrier torsional vibration. There is no obvious resonance of ring gear within the range of rotating speed change, so the ring gear floating range shall monotonously increase with the increase of rotating speed.
When the gears tooth are contacted, the impact force which is produced by different speed between two faces of gear teeth is smaller, and the impact energy is also small and will be rapidly consumed; then the driven gear starts to speed down to give rise to second impact, so the system shows periodical vibration. Thus, when the rotating speed is $100 \mathrm{r} / \mathrm{min}$, with effect of the gear impact, every impact between gears shall make floating trajectory generate larger deviation at instant. Therefore, the floating trajectory of center gear is regular and present $Z_{r}\left(Z_{r}\right.$ is the number of the ring gear teeth) leafy curves. When the speed increased, the difference in speed between gears also increases and the impact force shall gradually increase too; the system shall intensify vibroimpact. When rotating speed is $300 \mathrm{r} / \mathrm{min}$, the leafy curve in floating trajectory of sun gear shall show heterogeneous distribution; the sun gear trajectory is showing change trend to quasi periodical curve and the floating trajectory of ring gear still being regular. When rotating speed is $1000 \mathrm{r} / \mathrm{min}$, sun gear and planet gear show obviously vibroimpact; accordingly, the floating trajectory of sun gear is present noncyclic change and floating trajectory of ring gear showing regular radial curve. At this point, the sun gear generates beat vibration due to effect of the natural frequency of the sun gear torsion. At high speed, sun gear and planet gear show repeatedly impact of engagement and disengagement from time to time without regular pattern; the system vibration is changed to a typical chaos vibration. When rotating speed is $2000 \mathrm{r} / \mathrm{min}$, the floating trajectory of sun gear is changed into noncyclic curve; the floating trajectory of ring gear is changed into radial curve.

When input rotating speed is $2000 \mathrm{r} / \mathrm{min}$, the impact force between sun gear and planet gear shall increase; the system shows subharmonic resonance phenomenon, the time history of the sun gear microdisplacement along $x$ direction as shown in Figure 13(a). As frequency spectrum shown in Figure 13(b), the components around engaging frequency of the system are disorder in distribution, and the $1 / 2$ subharmonic component appeared. This phenomenon in gear system is also discussed in [9], in which it is verified existence by experiment.

\section{Conclusions}

This paper presents a novel modeling method of planetary gear system, in which the Hertz contact theory is induced to describe impact of the gear pairs under the condition of the high speed and light load. The vibroimpact characteristics of the system are analyzed; some interesting conclusions are obtained as follows:

(1) As input speed continuously increased under large load condition, the harmonic components of dynamic mesh load show radial distribution. The dynamic load obvious fluctuation appeared when harmonic components are around natural frequency of system.

(2) Under the light load condition, the vibroimpact phenomenon happened in planetary gear system. With increase of load, the main frequency component of impact force between the gears is changed 


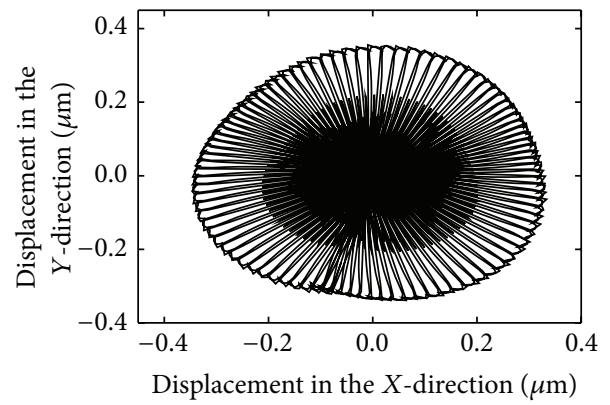

$n=100 \mathrm{r} / \mathrm{min}$

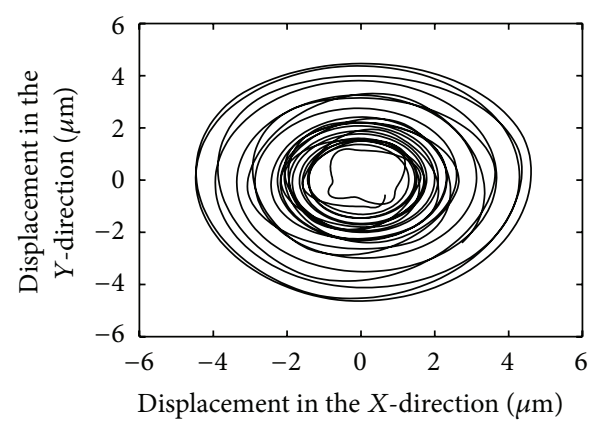

$n=1000 \mathrm{r} / \mathrm{min}$

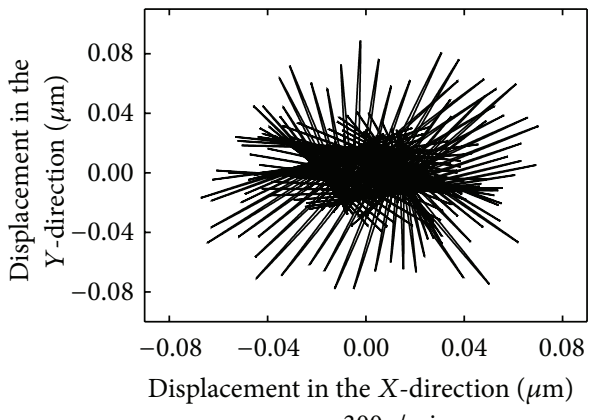

$n=300 \mathrm{r} / \mathrm{min}$

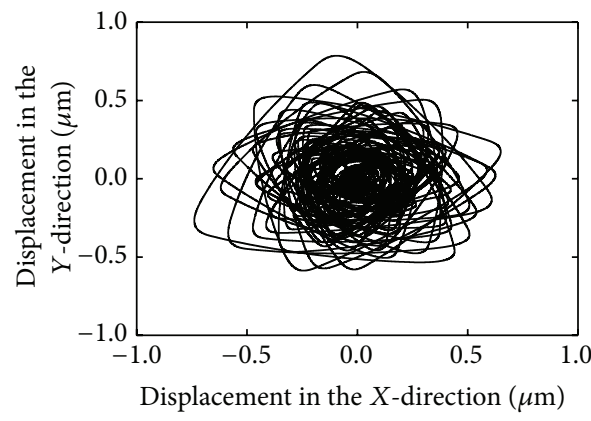

$n=2000 \mathrm{r} / \mathrm{min}$

(a) Floating trajectory of the sun gear

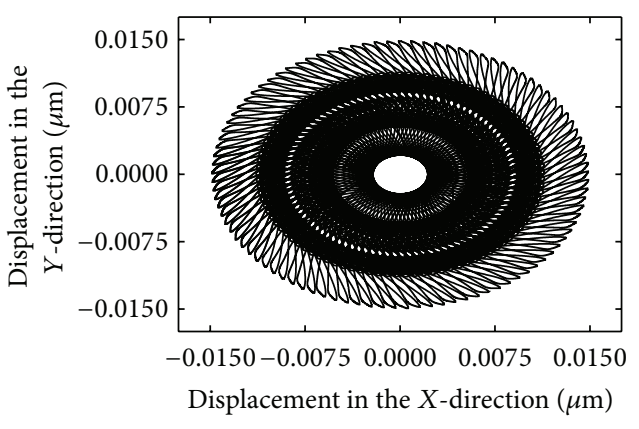

$n=100 \mathrm{r} / \mathrm{min}$

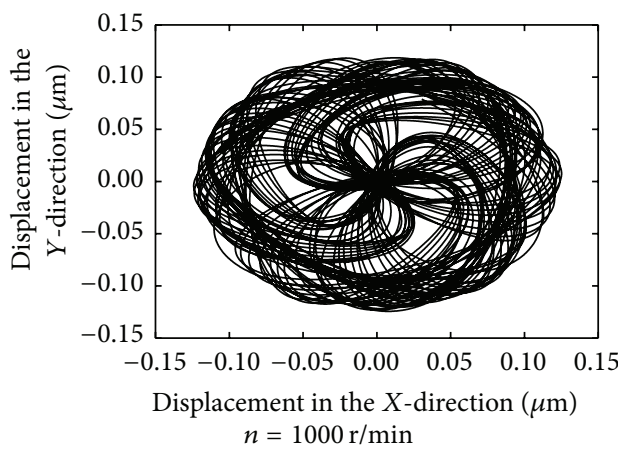

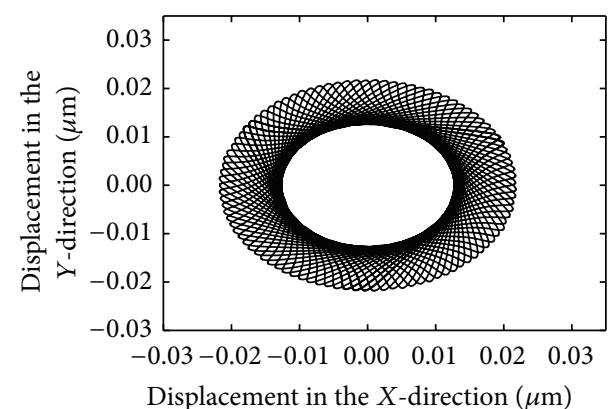

$n=300 \mathrm{r} / \mathrm{min}$

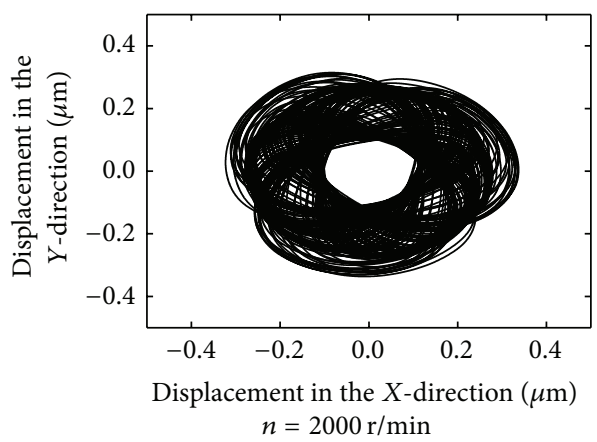

(b) Floating trajectory of the ring gear

FIGURE 12: Floating trajectory of center gear at various speed.

from the second harmonic component into engaging frequency component. Meanwhile, the time of gear mesh-apart is decreased continuously, till load is big enough to make gear system engaged normally.
(3) With increasing of input speed under the light load condition, the gear mesh-apart time shortens gradually; the relative speed of the gear pairs is increased, so vibroimpact of the system increased in intensity, and 


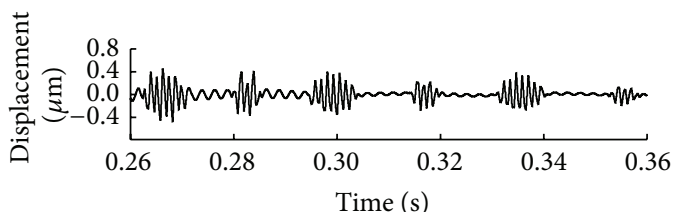

(a) The time history of the sun gear displacement in the $X$ direction $(\mu \mathrm{m})$

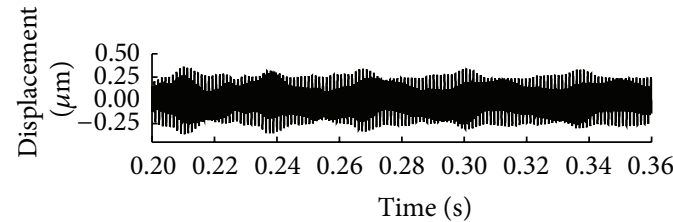

(c) The time history of the ring gear displacement in the $X$ direction $(\mu \mathrm{m})$

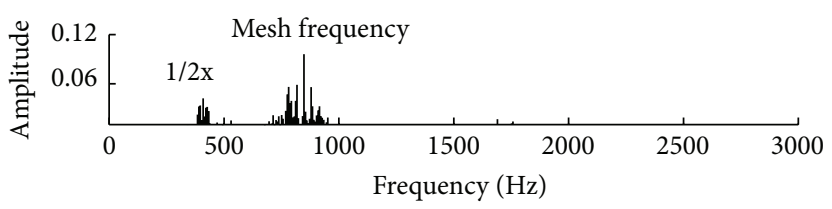

(b) The spectra of the sun gear displacement in the $X$-direction

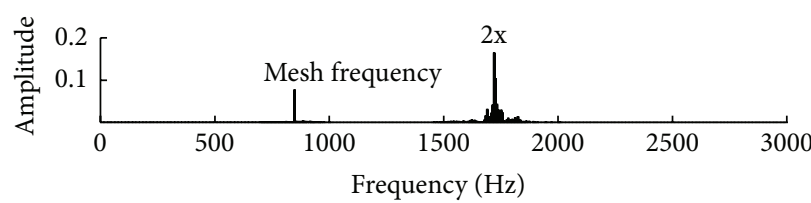

(d) The spectra of the sun gear displacement in the $X$-direction

FIGURE 13: Time history and frequency spectrum for displacement of center gear along $x$ direction at $2000 \mathrm{r} / \mathrm{min}$.

amplitude of impact force between the gears increased linearly.

(4) With increasing of input speed, the floating trajectory of the center gear is changed from regular leafy curves to the irregularly curves. Nonlinear feature of the center gear displacement can be observed at $2000 \mathrm{r} / \mathrm{min}$.

\section{Conflict of Interests}

The authors declare that there is no conflict of interests regarding the publication of this paper.

\section{Acknowledgments}

Thanks must be given to Xinjiang University for giving the authors a good surrounding and Natural Science Foundation of Xinjiang Province (2014211B004, XJEDU2014S009, and BS130120) for giving the authors a good financial backing to finish the most important part of this research.

\section{References}

[1] T. Sun and H.-Y. Hu, "Nonlinear dynamics of a planetary gear system with multiple clearances," Mechanism and Machine Theory, vol. 38, no. 12, pp. 1371-1390, 2003.

[2] W.-C. Ding and J.-H. Xie, "Advances of research on bifurcations and chaos in vibro-impact system," Advances in Mechanics, vol. 32, no. 4, pp. 513-524, 2004.

[3] H. J. Dong, Q. T. Chen, and Y. W. Shen, "On high speed impact and low speed contact in gear rattling," China Mechanical Engineering, vol. 17, no. 10, pp. 1068-1070, 2006.

[4] A. Saada and P. Velex, "An extended model for the analysis of the dynamic behavior of planetary trains," Journal of Mechanical Design, vol. 117, no. 2, pp. 241-247, 1995.

[5] D. Qin, M. Tian, and J. Yang, "Study on dynamic characteristics of gear transmission system of wind generator under varying wind load," Acta Energiae Solaris Sinica, vol. 33, no. 2, pp. 190196, 2012.
[6] Z. H. Bu, G. Liu, and L. Wu, "Natural characteristics analysis on herringbone planetary gear trains with slide bearing support," Chinese Journal of Mechanical Engineering, vol. 47, no. 1, pp. 8088, 2011.

[7] Y. Guo and R. G. Parker, "Dynamic analysis of planetary gears with bearing clearance," Journal of Computational and Nonlinear Dynamics, vol. 7, no. 4, Article ID 041002, 2012.

[8] L. Walha, T. Fakhfakh, and M. Haddar, "Nonlinear dynamics of a two-stage gear system with mesh stiffness fluctuation, bearing flexibility and backlash," Mechanism and Machine Theory, vol. 44, no. 5, pp. 1058-1069, 2009.

[9] A. Kahraman and G. W. Blankenship, "Interactions between commensurate parametric and forcing excitations in a system with clearance," Journal of Sound and Vibration, vol. 194, no. 3, pp. 317-336, 1996.

[10] T. Sun, Y. W. Shen, and Z. M. Sun, "Study on nonlinear dynamic behavior of planetary gear train solution and dynamic behavior analysis," Chinese Journal of Mechanical Engineering, vol. 38, no. 3, pp. 11-15, 2002.

[11] T. Eritenel and R. G. Parker, "Computational nonlinear vibration analysis of gear pairs using a three-dimensional model," in Proceedings of the ASME International Design Engineering Technical Conferences and Computers and Information in Engineering Conference, pp. 149-165, San Diego, Calif, USA, September 2009.

[12] M. Barthod, B. Hayne, J.-L. Tébeca, and J.-C. Pinb, "Experimental study of dynamic and noise produced by a gearing excited by a multi-harmonic excitation," Applied Acoustics, vol. 68, no. 9, pp. 982-1002, 2007.

[13] S. N. Doĝan, J. Ryborz, and B. Bertsche, "Design of low-noise manual automotive transmissions," Proceedings of the Institution of Mechanical Engineers Part K: Journal of Multi-body Dynamics, vol. 220, no. 2, pp. 79-95, 2006.

[14] Y. Kadmiri, E. Rigaud, J. Perret-Liaudet, and L. Vary, "Experimental and numerical analysis of automotive gearbox rattle noise," Journal of Sound and Vibration, vol. 331, no. 13, pp. 31443157, 2012.

[15] S. Li, "Effects of machining errors, assembly errors and tooth modifications on loading capacity, load-sharing ratio and transmission error of a pair of spur gears," Mechanism and Machine Theory, vol. 42, no. 6, pp. 698-726, 2007. 
[16] S. Li, "Effects of misalignment error, tooth modifications and transmitted torque on tooth engagements of a pair of spur gears," Mechanism and Machine Theory, vol. 83, pp. 125-136, 2015.

[17] A. Singh, "Application of a system level model to study the planetary load sharing behavior," Journal of Mechanical Design, vol. 127, no. 5, pp. 457-476, 2005.

[18] X. Zhou, Y. Shao, Y. Lei, and M. Zuo, "Time-varying meshing stiffness calculation and vibration analysis for a $16 \mathrm{DOF}$ dynamic model with linear crack growth in a pinion," Journal of Vibration and Acoustics, vol. 134, no. 1, Article ID 011011, 2012.

[19] C. G. Cooley, R. G. Parker, and S. M. Vijayakar, "A frequency domain finite element approach for three-dimensional gear dynamics," Journal of Vibration and Acoustics, vol. 133, no. 4, Article ID 041004, 9 pages, 2011.

[20] R. F. Li and J. Wang, System of the Gear Vibration Theory, Science Press, 1997.

[21] D. P. Jin and H. Y. Hu, Vibro-Impact and Control, Science Press, 2007. 


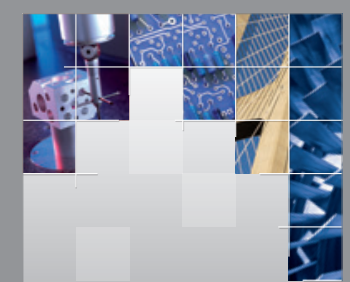

\section{Enfincering}
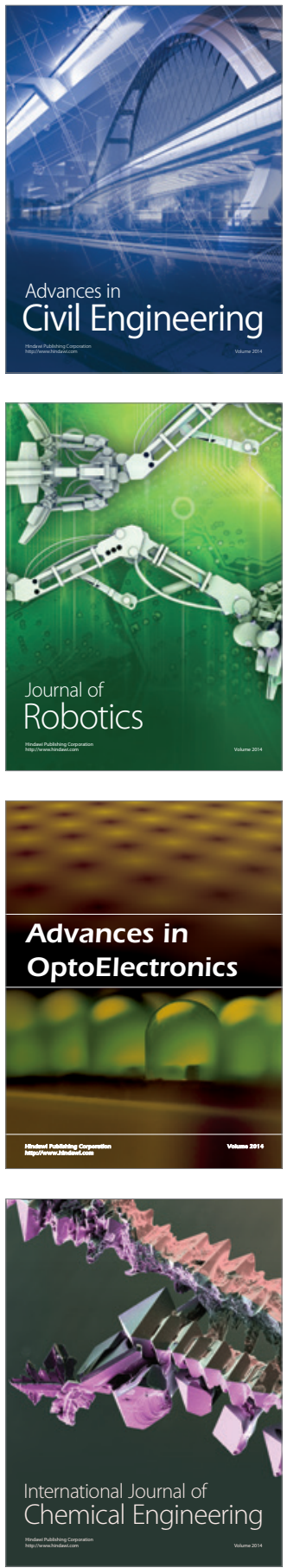

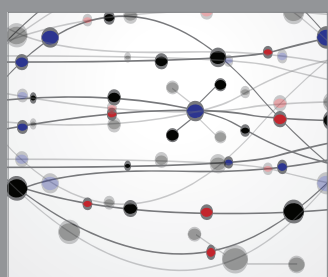

The Scientific World Journal

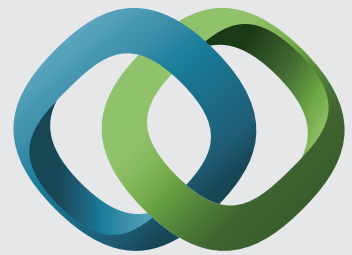

\section{Hindawi}

Submit your manuscripts at

http://www.hindawi.com
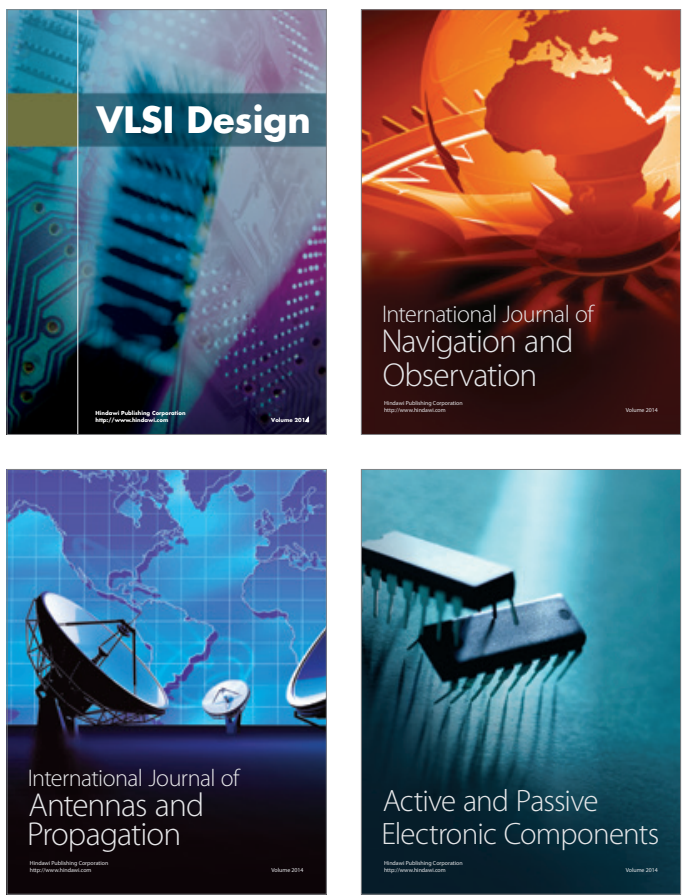
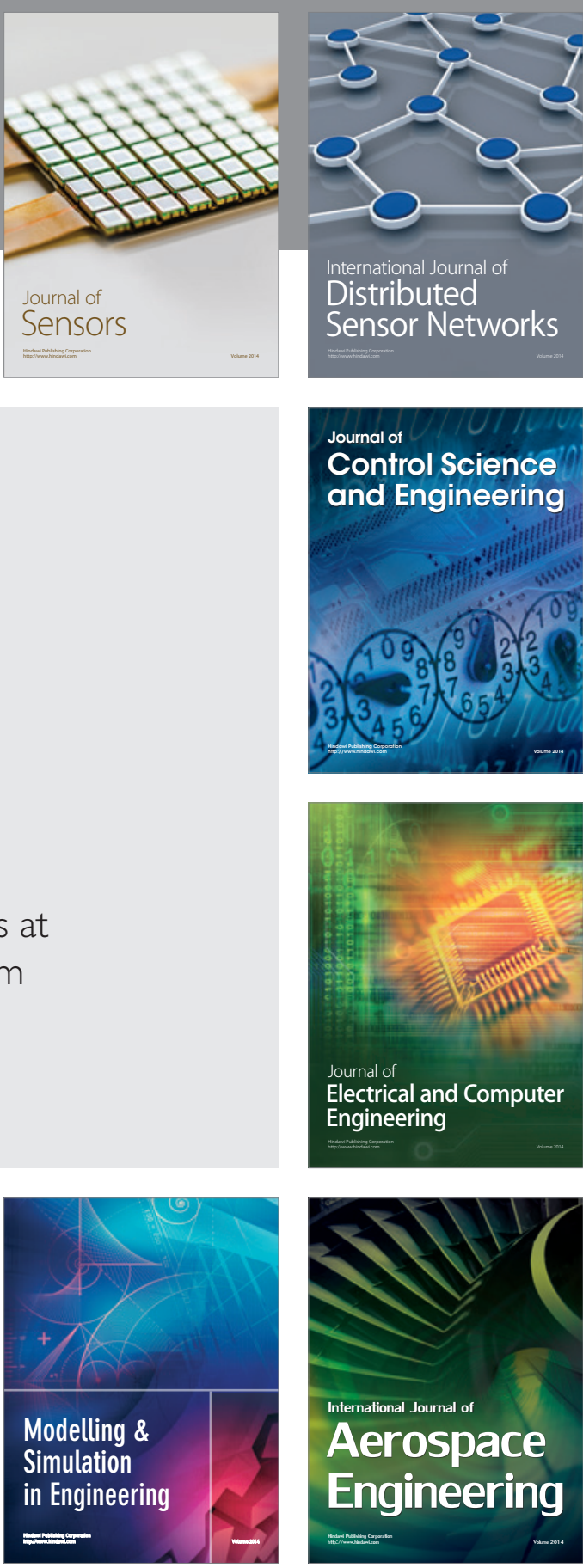

International Journal of

Distributed

Sensor Networks

Journal of

Control Science

and Engineering
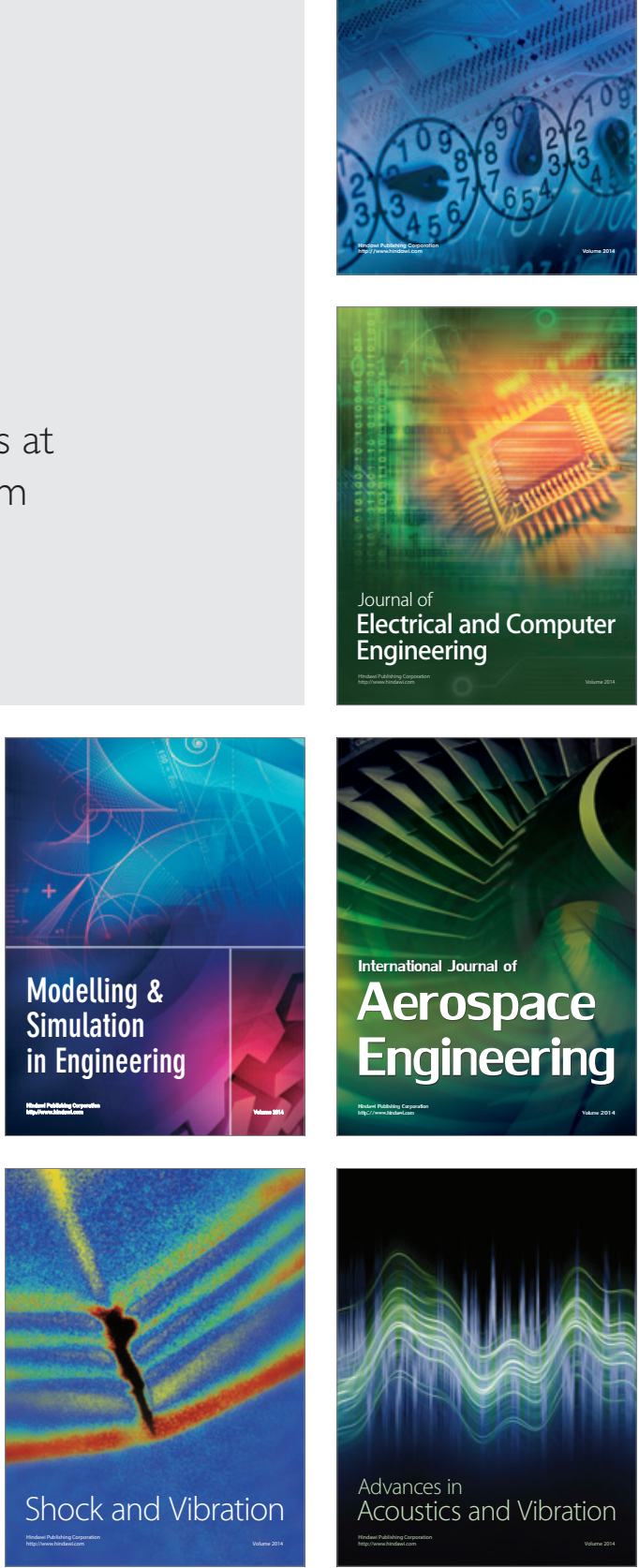